\title{
A comunalidad como dinâmica anticolonialista e epistêmica em Oaxaca - México
}

\section{La comunalidad como dinâmica anticolonialista y epistémica em Oaxaca - México}

\author{
Clarissa Noronha Melo Tavares \\ Universidade de Brasília - UnB \\ e-mail: clarissatavares3@gmail.com
}

\begin{abstract}
Resumo
A discussão apresentada nesse texto propõe refletir sobre a conexão entre a experiência e a formulação de pensamento indígenas, que aponta para a construção de uma epistemologia elaborada a partir das dinâmicas comunitárias indígenas de Oaxaca: a comunalidad. Tal categoria é analisada pela ótica do projeto decolonial e a ele se alinha ao realizar releituras próprias sobre o legado colonialista, indicando horizontes para atualizar a tradição crítica do pensamento latino-americano. Os dados apresentados nesse trabalho referem-se a experiências de luta e resistência dos povos do Istmo de Oaxaca contra a instalação de um megaprojeto de geração de energia eólica nos territórios indígenas.
\end{abstract}

Palavras-chave: pensamento decolonial, comunalidad, epistemologias do sul.

\section{Resumen}

La discusión presentada en este texto propone reflexionar sobre la conexión entre la experiencia y la formulación de pensamiento indígenas, que apunta a la construcción de una epistemología elaborada a partir de las dinámicas comunitarias indígenas de Oaxaca: la comunalidad. Tal categoría es analizada por la óptica del proyecto decolonial y a él se alinea al realizar relecturas propias sobre el legado colonialista, indicando horizontes para actualizar la tradición crítica del pensamiento latinoamericano. Los datos presentados en el trabajo se refieren a experiencias de lucha y resistencia de los pueblos del Istmo de Oaxaca contra la instalación de un megaproyecto de generación de energía eólica em los territorios indígenas.

Palabras clave: pensamento decolonial, comunalidad, epistemologias del sur.

\section{Introdução}

O presente artigo expõe reflexões que despontaram após um período de investigações envolvendo comunidades indígenas do Istmo de Oaxaca, no México, realizadas nos anos de 2008, 2009 e 2013, durante pesquisa de mestrado e doutorado. As realidades aqui apresentadas referem-se a comunidades dos municípios de Juchitán de Zaragoza (especificamente ao bairro da Sétima Seção - ou Bairro dos Pescadores - e à Colônia Álvaro Obregón) e de San Mateo del Mar, situados no Istmo de Tehuantepec, e 
focam o contexto de luta e resistência coletiva frente a tentativas de instalação de um megaprojeto de energia eólica nos territórios indígenas.

O que se propõe com esse texto é uma aproximação entre dois campos: a ação das comunidades indígenas do Istmo de Oaxaca, que têm em seu horizonte um ideal organizativo comunitário definido pela ideia de comunalidad ${ }^{1}$ - ainda que na prática esteja sujeito a imperfeições, desvios e contradições como qualquer modelo ideal -, e o pensamento acadêmico de autores preocupados em formular teorias capazes de elucidar realidades latino-americanas, que não aquelas baseadas em modelos eurocêntricos, e sim fundantes do pensamento decolonial (Quijano 1997, 2005; Mignolo 2005; Wallerstein 1992; Walsh 2013, Dussel 2016, Escobar 2012, entre outros).

A crítica decolonial, apesar de alinhada ao pensamento pós-colonial, propõe ir além ao problematizar as sociedades, os sujeitos e os conhecimentos a partir da colonialidade e não do colonialismo e, mais ainda, ao propor a elaboração de epistemologias a partir do seu próprio lugar, desbancando os cânones ocidentais da posição de inspiradores e bússola do pensamento latino-americano. O pensamento decolonial vem articular uma perspectiva que evidencia a faceta colonial da expansão capitalista no qual as Américas, como afirma Quijano (2005), não foram incorporadas a um sistema capitalista global já existente, mas, ao contrário, proporcionaram as condições econômicas para a existência dessa economia capitalista mundial. Com enfoque nesse aspecto, os autores decoloniais enfatizam o processo de subalternização de populações, saberes, epistemologias e cosmologias, constituído pela lógica eurocêntrica fundadora do imaginário nas diversas regiões colonizadas. Partindo dessa nova forma de compreender as relações sociais, econômicas, políticas e culturais no mundo, surge a necessidade de concepção de epistemologias baseadas em outros paradigmas metodológicos, elaborados a partir do Sul e dos sujeitos tidos historicamente como excluídos e subalternos, com destaque para a análise das relações de poder caracterizadas pelas diferenças de raça, etnia, gênero, classe, orientação sexual, entre outras.

Antes disso, Fanon ([1965] 2008) já dizia que para compreender os efeitos do colonialismo não se deveria atentar apenas para a intersecção das condições objetivas e históricas da dominação, mas para os discursos de inferiorização voltados aos colonizados. Ele defendia ser a civilização europeia a responsável pelo racismo colonial, uma vez que a inferiorização

\footnotetext{
${ }^{1}$ A utilização da escrita em espanhol dar-se por compreendermos que a tradução para o português "comunalidade", enquanto qualidade daquilo que é comunal, reduz a complexidade de significados originalmente atribuídos ao termo.
} 
é o correlato nativo da superiorização europeia. Precisamos ter a coragem de dizer: é o racista que cria o inferiorizado (Fanon op. cit.: 90). A inferiorização imposta pelo colonizador foi incorporada e reproduzida nos referenciais culturais do colonizado e o autor, francês da Martinica, evidenciou, partindo de seu local de origem, o vínculo indissociável entre colonialismo e racismo que perdura nas estruturas sociais das ex-colônias.

Quijano (1997, 2005), Mignolo (2005), Walsch (2013) e os demais pesquisadores envolvidos no projeto decolonial deslocaram o eixo de análise das discussões sobre modernidade/colonialidade, anteriormente focado em relações de dependência; em noções de superioridadeinferioridade, desenvolvimento-subdesenvolvimento; em projetos assimilacionistas e de homogeneização cultural, étnica e racial. Para esses autores, as teorias europeias sobre a modernidade não consideravam o papel central da colonialidade e tudo o que vem com ela - a exploração das riquezas naturais, a subjugação de povos e culturas, a violência, a imposição de padrões e visões de mundo etc. - enquanto condição que possibilitou a modernidade. Eles passaram a questionar o fato de a modernidade e a colonialidade não serem situações opostas, em que um polo representaria a superioridade, o avanço, o progresso sobre o outro atrasado, inferior, subalterno e, por isso, passível de ser subjugado. Em suas análises modernidade e colonialidade representam duas faces de uma mesma moeda.

As ideias eurocêntricas que nos fizeram crer na existência de antagônicos e desconectados modelos de organização política, econômica, social e cultural entre os países ditos "centrais" e os "periféricos" foram questionadas diante da relação de interdependência entre esses dois arquétipos. As regiões colonizadas, forjadas na escravização, violência e opressão das populações subalternizadas, bem como na exploração das riquezas e recursos naturais, ressignificaram a forma de enxergar-se nesse processo, refletindo sobre a herança colonial na América Latina a partir do seu lugar, o Sul, e das vozes aqui silenciadas e inferiorizadas.

A colonialidade é, dessa forma, a condição que se coloca para além do colonialismo, enquanto processo histórico marcado pela exploração política, social e econômica das metrópoles, e existe como parte do sistemamundo moderno. A colonialidade é, ao mesmo tempo, produto e causa das desigualdades entre o "centro" e a "periferia" da economia capitalista, é a expressão da desigualdade entre os Estados do sistema-mundo moderno e, afirma Wallerstein (1992), a etnicidade é a sua manifestação no seio de cada Estado. Todos os Estados, sem exceção, são compostos por grupos étnicos, 
tendo um grupo dominante e outros na posição de inferiores, complementa o autor.

Trazendo a discussão para o contexto mexicano, são vastos os registros que dão conta desse contexto colonial, bem como das diferentes estratégias que os povos indígenas passaram a engendrar a fim de não se dobrarem à lógica dos invasores. Entre os oaxaquenos podem ser identificados profusos acontecimentos visando à resistência sociocultural dos povos; à manutenção de línguas, cosmovisões e religiosidade; à soberania alimentar; ao controle econômico com o desenvolvimento de um comércio de curta e longa distância; à autonomia territorial.

Na região do Istmo de Tehuantepec, Avendaño (s/d) afirma que existem, de acordo com a mapoteca do Arquivo Geral da Nação, documentos históricos sobre, por exemplo, as comunidades de Huilotepec, Tehuantepec, San Dionisio del Mar, Juchitán, Sanatepeque, Guamelula, Iztactepec e Tzanaltepec. Tais documentos referem-se a antigos mapas da região e compõem um valioso conjunto de registros escritos da tradição figurativa zapoteca e do estilo de seus glifos, que Oudijk e Frizzo (2003) chamaram de títulos primordiais. Zeitlin (2003) acredita que a existência de tantos registros referentes a comunidades tão próximas fornece indicativos para considerar que esses mapas foram realizados pelos indígenas originalmente como apoio documental para as demandas que as comunidades apresentaram numa Real Audiência a fim de conservar sua autonomia territorial e política frente a Coroa Espanhola. Presume-se que esses documentos datem de meados do século XVI, no início da colonização na região.

Entretanto, apesar dos esforços para manterem formas autonômicas de sobrevivência, os povos originários do México, e da América Latina de forma geral sempre, estiveram no centro da dominação colonial, mesmo após a independência, como cativos do que Casanova (1963) chamou de colonialismo interno. Tal noção se concentra nas condições de exploração baseadas nas ideias de superioridade e inferioridade racial, concebidas não apenas entre Estados, mas internamente a um Estado, e está originalmente ligada à ideia da "conquista", à dominação de certos povos e culturas sobre outros, os quais não são totalmente exterminados e passam a responder a uma nova autoridade em condições de desigualdade, opressão e dominação.

No mesmo sentido que o colonialismo interno de Casanova, a colonialidade do poder (Quijano 1997, 2005) evidencia fortemente a ideia de raça e, em consequência, o racismo como princípio organizador da acumulação de 
capital e das relações de poder dentro do sistema-mundo moderno. A diferença entre conquistadores e conquistados esteve embasada na ideia da superioridade dos primeiros diante dos demais, constituindo um padrão de dominação não apenas do controle do trabalho, mas também de controle do Estado e suas instituições, bem como da produção de conhecimento.

A permanência do eurocentrismo e do ocidentalismo como imaginário dominante do mundo moderno permitiu legitimar a dominação e a exploração europeia de povos e culturas originárias da América Latina, transladados a uma condição de inferior. Aqui se vê a constituição do "outro"(Said 2007) como um ser não civilizado, inferior, sem religião, sem escrita, primitivo, sem desenvolvimento.

A consciência dessa dominação histórica conforma o ponto de partida do pensamento decolonial e das denominadas Epistemologias do Sul (Santos e Meneses 2010), que propõem rupturas na hierarquização dos saberes segundo o pensamento moderno ocidental e valorizam os saberes que resistiram a esse monopólio epistemológico construindo condições para o diálogo horizontal entre conhecimentos.

O surgimento dessas correntes que propõem ampliar a noção de ciência a partir de parâmetros não eurocêntricos vem atrelado ao momento de efervescência sociopolítica na América Latina, decorrente do processo de redemocratização iniciado na década de 1970 . O período foi marcado por contestações ao poder estatal, o ressurgimento de identidades étnicas e a fundação de novas relações entre Estados nacionais e populações diferenciadas, que propiciou um amplo movimento político e de reorganização interna de comunidades em contextos urbanos e rurais.

Até aquele momento, a forma de se compreender o contexto sociocultural dos países latino-americanos estive estritamente atrelada ao pensamento sociológico ocidental, no qual se projetavam as categorias marxistas que colocavam em foco questões relativas à luta de classes, às relações de trabalho no campo, à transformação dos trabalhadores rurais em operários do campo, entre outras.

No México, como em outras partes da América Latina, a influência desse pensamento levou a categoria de campesino a tornar-se intrínseca às identidades indígenas, o que pode ser atribuído à ênfase agrarista despertada pelo movimento revolucionário que, após a Revolução Mexicana de 1910, produziu leis que contribuíram para a desvalorização do elemento étnico, ao promover a redistribuição de terras aos camponeses, em vez de restituir os territórios indígenas: 
A Constituição de 1917 reconheceu aos 'nativos' o direito à restituição e confirmação de suas terras comunais, mas estas nunca foram consideradas como territórios indígenas. (Barabás 1994: 37).

A autora afirma que, devido à ausência de reconhecimento normativo do status diferenciado dos povos indígenas, estes não puderam reclamar legalmente seus direitos históricos, culturais e territoriais. A Constituição reconheceu a terra comunal (e não a terra indígena) enquanto propriedade das comunidades indígenas, cujo órgão supremo seria a assembleia geral e a organização da terra deveria obedecer às decisões do comissariado de bens comunais, eleito pela comunidade.

Por outro lado, as leis agrárias seguintes à Constituição também instituíram as terras ejidales (ou ejidos) visando regulamentar a posse coletiva das terras e a proibição de alienação das mesmas. A terra era doada pelo Estado a uma coletividade (geralmente composta por indígenas camponeses) e sua forma de utilização era regida por uma assembleia ejidal. O objetivo com a criação dos ejidos também era promover a reforma agrária, buscando desestruturar o sistema agrícola baseado em latifúndios, e fomentar as pequenas produções agrícolas familiares. Os indígenas foram incluídos nesse processo voltado primordialmente a atender uma demanda camponesa e passaram a receber ejidos, no entanto, é importante observar que, com relação ao direito à terra, os indígenas mexicanos foram considerados como sinônimos de camponeses (Tavares 2015).

Para se ter uma ideia da extensão de tal política no Estado de Oaxaca, segundo dados de 2012 da Secretaria de Desenvolvimento Agrário, Territorial e Urbano do governo federal mexicano, $78 \%$ das terras do estado são ejidales ou comunais, totalizando 850 ejidos e 714 áreas comunais, que ocupam uma extensão de mais de sete milhões de hectares, do total de aproximadamente nove milhões.

Sem se dissociar do componente camponês, indígenas de Oaxaca, alinhados ao contexto nacional e internacional das décadas de 1970 e 1980, promoveram o surgimento de movimentos étnico-regionais cujo arcabouço indentitário correspondia às suas bases comunitárias. Indígenas que tinham saído de seus povoados para estudar, motivados pela política educacional direcionada à população rural, voltaram às suas comunidades conjugando o conhecimento formal ao tradicional. Dietz (1995) fala que ocorreu uma reindianização desses intelectuais dentro da estrutura política das comunidades, cujo órgão supremo é a assembleia comunal. Alguns recuperaram o status jurídico-consuetudinário como comuneros, ou seja, 
membros da comunidade plenos de direitos, e ocuparam cargos da hierarquia cívico-religiosa tradicional. Os anciãos, que já haviam ocupado todos os cargos, passaram às funções intracomunitárias, enquanto os jovens assumiram as intermediações extracomunitárias.

Uma vez que as teorias eurocêntricas se mostraram insuficientes para a apreensão das realidades locais nesse contexto, intelectuais indígenas passaram a elaborar pensamento crítico a partir de suas lutas, de suas formas próprias de organização comunitária e visão de mundo. Floriberto Díaz (Mixe de Tlahuitoltepec) e Jaime Martínez Luna (Zapoteco de Guelatao) são importantes antropólogos indígenas de Oaxaca representativos desse momento de transformações e de formulação de novas espistemologias a partir de suas comunidades. Após estudar fora, eles retornaram e encabeçaram a tarefa de elaborar conceitualmente um referencial teórico explicativo sobre o modo de vida próprio em suas comunidades, as quais se encontravam em meio a disputas contra a invasão de seus territórios, a pilhagem de seus recursos naturais e em defesa de sua autodeterminação social, política, econômica, religiosa e cultural. Esse modo de vida comunitário indígena é definido por eles como comunalidad.

A comunalidad expressa princípios e verdades universais em relação à sociedade indígena, o que deverá ser entendido desde o início não como algo oposto, mas diferente da sociedade ocidental. Para entender cada um de seus elementos, é preciso ter em conta certas noções: o comunal, o coletivo, a complementaridade e a integralidade. Sem ter em mente o sentido comunal e integral de cada parte que pretendemos entender e explicar, nosso conhecimento sempre será limitado. (Díaz 2007: 40, tradução própria).

A partir da realidade Mixe, Díaz (op. cit.) conceitua que os elementos definidores da comunalidad são a terra, vista como mãe e território; o consenso em assembleia nas tomadas de decisões; o serviço gratuito, enquanto exercício de autoridade; o trabalho coletivo, como ato de recriação; e os ritos e cerimônias, na qualidade de expressão do dom comunal.

O autor situa a comunalidad a partir do debate sobre autonomias indígenas. Ele fala que as discussões sobre o tema não podem surgir somente de embates teóricos, mas devem vir, sobretudo, da reflexão acerca das 
realidades concretas nas quais se evidenciam práticas autonômicas apesar de e contrárias ao Estado-nação (op. cit.: 34).

Já Luna (2003) fala que a comunalidad, como forma de existência e de pensamento, origina-se na história do despojo, enquanto uma maneira de os povos indígenas relacionarem-se com os territórios e recursos após a "conquista", sendo, dessa forma, ela também, fruto da história colonial. Exercer a comunalidad está associado ao exercício da autodeterminação sobre os territórios que os povos ocupam tradicionalmente, à possibilidade de exercer influência e controle sobre o que ocorre nesses espaços, de participar como coletividade das decisões que afetam as terras comunais e os recursos existentes e de ser reconhecida a forma própria de governo comunitário.

Assim como no pensamento decolonial, os intelectuais aoxaquenhos questionam o legado do colonialismo na sociedade atual, em especial, na relação entre os povos indígenas e o Estado. Colocam-se enquanto sujeitos históricos e contemporâneos capazes de pensar seu lugar no mundo e reinventar suas formas de resistências. Trazem para o campo teórico uma realidade concreta, o exercício da comunalidad, enquanto dinâmica de superação das relações hierárquicas no interior do Estado mexicano, vinculadas historicamente ao racismo e à inferiorização dos povos, e enquanto categoria capaz de pôr em debate uma epistemologia própria, comunal e a partir do Sul.

Esteva (1997) entende demanda por autonomia dos povos indígenas, traduzida pela comunalidad, implica, acima de tudo, respeito e reconhecimento pelo que eles já têm, ou seja, o reconhecimento da jurisdição e dos territórios de cada povo indígena. A jurisdição refere-se aos sistemas normativos internos, às formas próprias de governo e às normas e instituições específicas para a atenção de suas necessidades. O poder não é delegado a governantes que se tornam independentes dos governados. Já o território é compreendido como um exercício de responsabilidade sobre a natureza e a sociedade. Na vivência da comunalidad, os povos indígenas constroem suas formas de resistência, suas lutas por autodeterminação e fortalecem seu autogoverno, apostando na construção de concepções pluralistas em substituição às concepções indigenistas nas relações entre os povos indígenas e o Estado.

Apesar de ter sido inicialmente utilizada como modelo explicativo das sociedades indígenas da Serra Norte de Oaxaca, pelas elaborações Díaz e Luna, o alcance epistêmico da comunalidad pode expandir-se a diversas realidades indígenas de Oaxaca, que compartilhem valores e modos de vida 
resultantes do encontro entre as matrizes culturais mesoamericanas e os processos coloniais e indigenistas estatais.

No Istmo de Oaxaca, região que interessa mais diretamente a este trabalho, a comunalidad é um conceito aplicado pelo Binnizá (Zapoteco) Carlos Manzo para nomear a dinâmica social indígena istmeña.

A comunalidad é um sistema indígena de relações intracomunitárias e regionais que tem dado sustento à autonomia que de fato se vive em diversos povoados indígenas de Oaxaca e do México, através da realização de assembleias, privilegiando o consenso na tomada de decisões $e$, em alguns casos, focalizada na defesa e no aproveitamento da terra, territórios e recursos naturais, entrando em conflito com o marco do Plano Puebla Panamá, com os interesses privatizadores das empresas transnacionais e governos que estão impondo esses projetos no Sul e Sudeste do país. A comunalidad (...) representa um sistema de relações intra $e$ extracomunitárias que permitiram a resistência do modo de vida dos povos indígenas em diversos momentos históricos, como a invasão, a colônia, o liberalismo e o neoliberalismo. (Manzo 2008: 68, tradução própria).

A um só tempo, a comunalidad se estabelece, pelas mãos dos intelectuais oaxaquenhos, como categoria teórica, que expressa um pensamento com potencial epistemológico e emancipatório (Aquino, 2013), e como uma experiência, que se materializa por meio da convivência e do exercício de funções comunitárias. De forma geral, Rendón (2004) define os princípios fundamentais da comunalidad a partir de quatro elementos: o poder comunal, o trabalho comunal, as festas comunais e o território comunal. Propomo-nos aqui a descrever, analisar e refletir sobre as situações empíricas formadoras dessa categoria.

\section{O poder comunal}

Vivenciado de forma compartilhada, obrigatória e cotidiana, o poder comunal está alicerçado em duas instituições, a assembleia comunal e o sistema de cargos. Uma é diretamente vinculada à outra, sendo a assembleia o órgão máximo de governo local e também sua instância eleitoral. Ela é um dos momentos mais importantes de representação do poder político e é através dela que a comunidade debate e consensua suas decisões, bem como elege suas autoridades (Tavares 2015). 
O exercício do poder comunal nas comunidades indígenas de Oaxaca levou ao reconhecimento oficial de um mecanismo tradicional indígena: o sistema de "Usos e Costumes", que foi acolhido pela Constituição do Estado de Oaxaca, em 1998. Os "Usos e Costumes" compreendem um procedimento normativo através do qual as comunidades elegem seus governantes em assembleias comunais que são regidas por suas próprias regras e de forma diferenciada da estrutura jurídico-administrativa implementada pelos partidos políticos. Para dar uma ideia da força desse sistema, dados de 2010 do Instituto Nacional de Estatística e Geografia (INEGI/México) apontavam que dos 570 municípios oaxaquenhos, 418 eram regidos por Usos e Costumes, enquanto 152 mantinham eleições via partidos políticos. Os municípios que se regem por usos e costumes são aqueles que se organizam a partir de coletividades indígenas e continuam a reconhecer-se como tal, comumente denominados de pueblos. Esta forma de regime, porém, não está a salvo de interferências e conflitos causados por interesses externos às comunidades, que muitas vezes vão de encontro ao exercício da comunalidad, e operam sob influência dos partidos políticos.

No México e em outros países latino-americanos em que estão previstos os sistemas normativos indígenas (tais como Bolívia e Equador), há discussões críticas acerca do termo "usos e costumes", por este apontar para uma subordinação dos sistemas jurídicos indígenas ao direito nacional positivo. Chenaut et al. (2011) indicam que a apropriação indígena da linguagem do direito, enriquecida de sua visão enquanto povos, trazem a exigência de uma profunda transformação dos Estados nacionais para que estes reconheçam e pratiquem o pluralismo jurídico.

No caso mexicano, ainda que se discuta que a mudança na Constituição serviu apenas para que as normas consuetudinárias já vigentes nos municípios adquirissem um status legal, para Hernández-Díaz (2005) as mudanças também se converteram em um espaço para a defesa da identidade coletiva, primeiro das comunidades e municípios, e depois da organização política dos povos indígenas.

A segunda instituição do poder comunal é o sistema de cargos civis e religiosos que compõe a estrutura organizativa das comunidades. A ocupação de tais cargos, também determinada nas assembleias comunais, visa a nomear os membros qualificados a exercerem funções determinadas no organograma específico de cada pueblo, que possui regras e normas próprias. Segundo a experiência de Luna (2002), para que um cidadão obtenha representatividade nesse sistema de poder comunal composto por assembleias e sistema de cargos é necessário que, desde criança, tenha demonstrado um profundo respeito pela comunidade. A formação para a 
cidadania comunal é iniciada ainda criança com tarefas relacionadas ao cuidado da igreja e trabalhos agrícolas. Com o passar do tempo as atividades vão se diversificando e a educação é consolidada através do trabalho comunitário. Dessa forma, a educação combinada à participação, ao trabalho e à representatividade constituem aspectos de uma pedagogia diferenciada, não sistematizada de maneira formal, mas que resulta num exercício de poder comunal.

Em pesquisa realizada no ano de 2013 (Tavares 2015), na Colônia Álvaro Obregón ${ }^{2}$, foi possível observar a experiência comunitária de retomada do poder comunal dos Binnizá (Zapoteco) por meio da restituição da assembleia geral como forma de eleger os representantes políticos. Esse processo teve início com a mobilização de moradores contrários à instalação de um projeto eólico em terras comunais. Antes da chegada da empresa Mareña Renovables, responsável pelo projeto, a comunidade era governada politicamente por representantes indicados pelo prefeito de Juchitán, uma vez que a Colônia é uma agência vinculada àquela sede municipal. Com a organização comunitária em torno da oposição ao projeto eólico, a comunidade retomou sua Assembleia Geral de Cidadãos e decidiu que, a partir de então, seria governada por seus representantes eleitos através dela. Em reação à ameaça de perder seu território para a empresa, os Binnizá resgataram essa forma de poder comunal que estava em desuso e, no entanto, é parte do exercício de sua comunalidad, adotando o sistema normativo de usos e costumes.

Os desentendimentos gerados a partir da disputa com a empresa levaram os indígenas a questionar a postura do prefeito de Juchitán e da autoridade de Álvaro Obregón em prol dos interesses do empreendimento em detrimento aos dos moradores. Essa consciência gerou uma importante decisão comunitária: a de não mais aceitar governantes locais indicados pelos partidos políticos.

Desse modo, a Assembleia Geral de Cidadãos de Álvaro Obregón elegeu, no dia 8 de dezembro de 2013, o corpo do cabildo comunitário, para executar as funções político-administrativas na comunidade. Disseram alguns Binnizá presentes que, apesar de a maioria da população apoiar a retomada da Assembleia de Cidadãos para eleger seus representantes, havia um pequeno grupo que estava dividindo a comunidade por se colocar a favor da instalação do projeto eólico à espera de ser recompensado por isso. Outros relataram que a eleição das autoridades após tanto tempo era um desafio,

\footnotetext{
2 Administrativamente, a Colônia Álvaro Obregón (Gui'xhi' Ro'em binnizá) é uma agência de Juchitán, distante cerca de $20 \mathrm{~km}$ da sede do município. Lá vive uma comunidade indígena Binnizá, composta por 3.558 pessoas.
} 
pois, enquanto alguns lutavam para retomar o sistema normativo indígena, outros estavam envolvidos com os partidos políticos a tal ponto de tomarem decisões desfavoráveis à comunidade. Alguns também temiam que, se por um lado a eleição poderia designar um representante contrário ao projeto eólico e alinhado às posições da maioria dos Binnizá, por outro, poderia cair na armadilha de legitimar alguém ligado aos partidos e que fosse, por consequência, agir motivado pelos interesses das empresas.

Após a manifestação em zapoteco de alguns moradores ao microfone, teve início a eleição propriamente dita. A dinâmica consistia em chamar os nomes dos candidatos para cada cargo, que se apresentavam à frente e eram aprovados mediante palmas do público. Assim foram eleitos, por consenso, 14 representantes para o triênio 2014-2016, com o objetivo de desempenhar funções como de administrador, juiz, agente comunitário, síndico e para ficarem responsáveis por áreas como saúde, educação, pesca, entre outras. Dos 14 eleitos, apenas uma era mulher, a tesoureira Adelita Guerra Vicente.

Na ocasião, a praça estava cheia e a população bastante envolvida com o processo que era conduzido majoritariamente na língua zapoteca e, em alguns momentos, traduzido ao espanhol para que os visitantes pudessem acompanhar as discussões. Ficou evidente que a eleição na praça principal consistia no momento público de legitimação da Assembleia Geral de Cidadãos sobre uma decisão que já havia sido discutida e consensuada em momentos internos da comunidade, anteriores àquele. Ali a comunidade expressava o sentido mais simbólico da escolha dos representantes políticos por meio da assembleia, num momento que tratava de tornar pública a decisão comunitária de retomar suas formas próprias de poder comunal, assim como de apresentar os membros comunitários que seriam responsáveis por representar político e administrativamente a comunidade.

Entre os presentes, a importância da retomada da assembleia para a escolha das autoridades locais foi relatada em dois sentidos. Inicialmente, pelo fato de ser a primeira vez que isso aconteceu entre a geração que esteve à frente desse processo. As pessoas tinham referências da utilização dos usos e costumes em tempos passados, mas não sabiam há quanto tempo vinham seguindo o regime político-institucional-oficial baseado nos partidos políticos. Em segundo lugar, porque se deram conta de que essa é uma das características que os define como povos indígenas e que fortalece sua autonomia: isso nos faz retornar às nossas raízes e aos nossos antepassados, repetiam. 
Tal decisão possibilitou à comunidade de Álvaro Obregón realizar um mergulho em si mesma e rever comportamentos comunitários que estavam acontecendo de forma inconsciente e automática, desvinculados da comunalidad.

A assembleia se estabeleceu através do movimento de resistência possibilitando a unificação do povo e também dando lugar para que o povo tomasse nas suas mãos a autonomia para a defesa do nosso território. A assembleia é o órgão máximo, que tem a última palavra e que faz o povo soberano e nós nunca tínhamos feito isso antes. Agora temos consciência de que precisamos fortalecê-la porque estamos apenas começando. (Pedro Lopez Orozco, Binnizá de Álvaro Obregón, em entrevista à autora, 2013).

\section{O trabalho comunal}

Da mesma forma que as decisões políticas, o trabalho regido pela comunalidad é comunal. A reciprocidade e a participação no trabalho são características básicas das relações de nível intra e interfamiliar e comunitária. No que se refere ao trabalho comunal, elas estão presentes em suas três formas: o trabalho no exercício do poder, o trabalho na vida econômica e o trabalho na consolidação festiva e ritual da identidade (Maldonado 2002).

Tanto Floriberto Díaz (2007) como Jaime Luna $(2002,2003)$ destacam a vontade e a capacidade de doação de trabalho para a comunidade como o principal valor da comunalidad. E é a partir do trabalho econômico e político que eles acreditam que os povos indígenas podem defender seu território e seguir uma vida autodeterminada. A materialização do trabalho comunal acontece por meio da prestação de serviços comunitários, sendo uma das formas o já citado cumprimento de cargos públicos destinados a servir à comunidade. $O$ cumprimento dos cargos é obrigatório e os membros designados para ocupá-los não recebem remuneração por tal atividade. Eles devem cumprir seu dever como uma prestação de serviço à comunidade. Cada pessoa ocupa, ao longo da vida, diferentes funções e, em princípio, as responsabilidades e o prestígio que vêm com as funções aumentam progressivamente.

Todos os membros da comunidade também devem participar regularmente dos trabalhos coletivos (tequios) e outros serviços. O tequio (do náhuatl téquitl, trabalho ou tributo) é uma forma organizada de trabalho em benefício coletivo que pode ter diversas variações. Pode tratar-se de um 
trabalho físico para a realização de obras públicas: estradas, edifícios, limpeza, trabalho agrícola etc.; ou ajudar na realização das festas comunitárias, de tal forma que os convidados não passem fome ou sede. Pode também significar um trabalho intelectual, ou seja, colocar a serviço da comunidade os conhecimentos adquiridos em escolas e universidades.

O sentimento de comunidade é que alimenta o tequio de sentido. Esse trabalho coletivo comunitário, para o qual não se recebe pagamento e é obrigatório, expressa a capacidade de jää'y combinar seus interesses individuais e familiares com os interesses da comunidade (Díaz 2007: 59).

Se o tequio designa o trabalho comunitário obrigatório, existe outra modalidade de trabalho comunal que na língua zapoteca é nomeada por guelaguetza ou galges (para os Zapoteco do Vale); gozona ou gwzon (na Serra); e ainda gendalizaa (para os istmeños), que pode ser traduzida como ajuda ou trabalho recíproco (Manzo, 2003). É uma variação do tequio na relação entre famílias. Essa forma de trabalho possibilita a uma família convidar seus vizinhos para construir uma casa, trabalhar na sua lavoura, no conserto de um telhado etc., selando um compromisso, sem nenhuma mediação escrita, de retribuir-lhes a ajuda quando dela precisarem (Díaz op. cit.).

Entre os indígenas da Colônia Álvaro Obregón, bem como entre os da Sétima Seção de Juchitán, foi possível observar, durante os períodos de campo, a rede de solidariedade quanto à realização de tarefas, que rege o convívio e a interação social binnizá. Desde os menores gestos cotidianos voltados à coletividade, como a preparação e o compartilhamento de alimentos ao longo de reuniões, a preocupação e o cuidado constante com os companheiros ameaçados, a disposição para redigir textos de divulgação das denúncias e ações dos indígenas, a limpeza e a responsabilidade pelos espaços coletivos como a Rádio Totopo e os locais de barricada4; até as ações mais excepcionais ou direcionadas ao auxílio de uma família em particular.

Sobre esse último aspecto, fui possível observar, em 2015, os preparativos para uma festa de casamento da filha de Pedro Lopez Orozco, mayordomo importante liderança comunitária responsável por financiar a festa patronal de sua comunidade - na Colônia Álvaro Obregón. Logo cedo,

\footnotetext{
${ }^{3}$ Quer dizer ser humano na língua mixe/ayuuk (Díaz 2007).

${ }^{4}$ A Rádio Totopo está localizada no bairro da Sétima Seção de Juchitán e se constitui em uma importante rádio comunitária indígena, que desempenha papel fundamental na organização e resistência das comunidades frente aos projetos eólicos que tentam se fixar nas terras comunais da região. As barricadas correspondem a acampamentos montados em locais estratégicos pelos indígenas para impedir a passagem das empresas para dentro das terras comunais. Devido ao amplo movimento de resistência aos projetos eólicos, muitos indígenas que estão à frente dessas mobilizações sofrem perseguições e ameaças (Tavares 2015).
} 
chegaram à casa de Pedro alguns moradores para ajudar com os preparos das comidas e do espaço. Enquanto os homens arrumavam o local, dispondo as mesas e os toldos, as senhoras dividiam-se entre a fabricação de tortilhas, caldos, carne cozida e outros alimentos a serem servidos durante a festa. Outras mulheres cuidavam de empacotar salgadinhos, amendoins e doces para as crianças. Em um determinado momento, um grupo de senhoras chegou para oferecer comidas que tinham feito para ajudar a família da noiva. Foram recebidas com certa cerimônia, na sala de estar, e em troca, lhes foram ofertados presentes como vassouras, refrigerantes e biscoitos. Pedro relatou que essa era uma tradição entre eles.

Manzo (1993) trata essa forma de guendalizaa específica por guna: é a entrega em espécie de que fazem as mulheres por ocasião de um casamento: galinhas, ovos, arroz. É o apoio em espécie (ibidem: 151). Traduz ainda a guendalizaa por "aparentar", ou seja, tornar-se parente mediante uma ajuda a quem a requer.

\section{As festas comunais}

A comunalidad está repleta de ações estabelecidas de maneira obrigatória. No entanto, diferentemente do caráter imperativo do cumprimento de cargos públicos e do tequio, existem as festas da comunidade que são atos de solidariedade, assim como a guendalizaa. A solidariedade durante as festas ultrapassa os limites da comunidade e pode estender-se a uma relação com os pueblos vizinhos.

As festas e os rituais que cada comunidade realiza são resultados de um ano do trabalho agrícola, artesanal, comercial ou produtivo e, por meio delas, é possível perceber entre os integrantes a necessidade de sobreviver como coletividades com culturas diferenciadas (Luna, 2002). As festas são o momento máximo de socialização comunitária em que todos os membros trabalham para executá-la e também para estar presente e participar da celebração em si. Através dessas comemorações promove-se a reprodução cultural e a afirmação dos valores e costumes tradicionais.

Apesar de haver diferentes motivos para as celebrações, pode-se falar que uma é considerada a festividade que conquistou maior visibilidade em Oaxaca: a (também nominada) Guelaguetza. Alguns autores afirmam que suas origens remontam à época pré-hispânica e estão relacionadas ao culto da divindade do milho. Jancsó (2003) destaca que, apesar do que se possa dizer sobre os antecedentes indígenas da Guelaguetza, a festividade tal como se conhece na atualidade é produto de uma mistura entre a cultura indígena e a espanhola. 
Entre os anos 1960 e 1970, a Guelaguetza começou a ser convertida na megafestividade que se conhece atualmente e atrai milhares de turistas, com uma programação que inclui 10 dias de festa na capital Oaxaca de Juárez, patrocinada pelo governo, com atrações gastronômicas, artesanais, apresentações teatrais e de dança, desfile de delegações, feiras e outras atividades. Além dessa superprodução que compõe o calendário oficial do estado, muitas comunidades indígenas seguem realizando suas próprias Guelaguetzas com uma menor interferência externa e maior sentido comunitário.

Antes de nomear a festa, a palavra guelaguetza ou guendalizaa (para os Zapoteco do Istmo) pode significar, além de trabalho recíproco como visto acima, oferenda, presente ou apoio mútuo. Está relacionada com as relações de solidariedade que unem a população e servem para criar uma rede de cooperação entre famílias, povos, comunidades e municípios. As tradições em volta da guelaguetza definem o povo oaxaquenho desde tempos passados até hoje.

É um costume nas comunidades indígenas oaxaquenhas oferecer guelaguetza (comidas, bebidas, dinheiro) nos casamentos, batizados, festas, nascimentos e funerais. Jancsó (2003) menciona outro costume, da época colonial, com a mesma denominação, segundo o qual os indígenas costumavam levar os primeiros frutos da safra aos fazendeiros espanhóis cujas terras cultivavam. Uma das teses sobre a associação do nome guelaguetza à festa é devido ao fato de os produtores, durante os festejos, levarem produtos da sua região (frutas, produtos artesanais etc.) para dar de presente ao povo e aos representantes do governo.

Para os juchitecos, no entanto, são as chamadas velas as maiores festividades na região, que ocorrem em grande parte no mês de maio, concentrando mais de 15 cerimônias por ser a época das chuvas e das primeiras colheitas, mas também acontecem em agosto, setembro e dezembro. Há velas dedicadas aos santos (como as de San Vicente Ferrer, patrono de Juchitán), outras a ofícios (tais como a dos pescadores e a dos agricultores) ou, ainda, em homenagem a famílias de estirpe (Nava 2013).

Segundo Manzo (1993), o sentido ritual dos elementos que aparecem nas festas atualmente é resultado da conjugação entre elementos da cultura pré-hispânica e espanhola, e, por isso, as festividades podem ser celebradas por diversos motivos que vão desde a comemoração a um santo como a uma planta ou um animal.

Além do aspecto festivo-religioso, as festas também têm adquirido, ao longo do tempo, um caráter etnopolítico, enquanto espaço que promove, ao 
mesmo tempo, a afirmação cultural, a reivindicação de direitos e o posicionamento comunitário frente a elementos externos, tais como os empreendimentos eólicos. Foi possível acompanhar a realização de uma dessas festividades, realizada em 14 de dezembro de 2013, a peregrinação da Santa Cruz dos Pescadores (Santa Cruz Guuze Benda), quando cerca de mil Binnizá percorreram o caminho que liga Juchitán a Unión Hidalgo e observaram, pela primeira vez, o impacto causado pelos maquinários e pelas turbinas eólicas em terras onde antes se plantava uma espécie tradicional de milho (xuba huinı).

As peregrinações e as velas acontecem em dois momentos distintos, mas são eventos que se complementam na manutenção de tradições e no calendário festivo-religioso dos istmeños. A Vela dos Pescadores e a peregrinação da Santa Cruz dos Pescadores, da qual participei, são promovidas pela Sétima Seção de Juchitán, por meio da Sociedade de la Santa Cruz de los Pescadores formada por um grupo de associados. A cada ano, um deles se candidata para ser o responsável por organizar as festividades, ser o seu mayordomo (o patrocinador da festa), que para isso contará com a ajuda de sua família e da própria Sociedade. O encargo gera prestígio e é visto como uma forma de generosidade para com a comunidade a qual pertence. Àquela época, alguém que se candidatasse a mayordomo da Vela dos Pescadores precisaria esperar cerca de 15 anos até conseguir o feito, devido à extensa lista de pretendentes (Tavares 2015).

O trabalho coletivo não remunerado é o elemento que define e permite a realização das festividades. $O$ dinheiro tem um papel importante, pois é o que possibilita que as velas e as peregrinações sejam realizadas, no entanto, não se reveste do sentido capitalista ou da ganância (Manzo 1993: 152), pois contribuir com as festas é visto como um ato de entrega do seu trabalho e de redistribuição das riquezas. As celebrações tanto das velas como das peregrinações duram vários dias e incluem os momentos de preparação, além do evento propriamente dito.

A guendalizaa (trabalho coletivo) pôde ser observada em cada detalhe para a realização da peregrinação da Santa Cruz dos Pescadores. Para receber os peregrinos, o percurso foi limpo dias antes, assim como o local de chegada foi preparado com a limpeza do terreno, a montagem de estruturas para o pernoite dos participantes, a pintura e decoração da capela, tudo feito de forma colaborativa por membros da comunidade.

No dia do evento, durante a madrugada, o mayordomo e sua família abriram as portas de sua casa, onde se encontrava a Santa Cruz ornamentada com flores de guie chaachi (jasmin) e serviram chocolate e pão doce aos 
visitantes que estavam lá para acompanhar a saída da Santa Cruz. As pessoas entravam na sala onde a cruz apresentava-se exposta para rezar e fazer pedidos e, por volta das seis horas da manhã, teve início a peregrinação pelas ruas da Sétima Seção de Juchitán.

Em diferentes pontos da peregrinação, que totalizou 15 quilômetros, os sitiantes que moravam no caminho ofereciam comida e bebida aos participantes. Uma banda de música ditava o ritmo por todo o trajeto e algumas famílias se deslocaram dias antes da festa para cuidar do preparo das comidas com as quais receberiam os peregrinos. Essas famílias são as que têm um posto no local de chegada, ou seja, um espaço para acomodar seus convidados e compartilhar a comida e a bebida.

Durante a caminhada, aconteceram alguns momentos de constrangimento. O bairro da Sétima Seção, naquele 2013, estava dividido pelos conflitos provocados em decorrência das pressões pela construção do Parque Eólico Bií Hioxho, nas terras comunais dos Binnizá de Juchitán. Assim, na primeira parada, na casa de Francisco López Chente, nem todas as pessoas entraram e se serviram, tendo em vista o anfitrião estar envolvido com o arrendamento de terras comunais para o projeto eólico. Parte do grupo que acompanhava a peregrinação decidiu seguir a caminhada ou esperar mais à frente, sem parar naquele ponto.

Em outra parada, dessa vez no rancho de Mariano Santana, ex-prefeito que dera permissão à empresa Gás Natural Fenosa entrar em terra comunais sem realizar consultas aos comuneros, todos os peregrinos entraram, comeram o que lhes foi oferecido e aproveitaram a sombra largas das árvores para descansar do percurso por alguns momentos. Era um sítio com uma extensa área e boas instalações, onde a fartura de comida e bebida evidenciavam a abundância de recursos dos proprietários.

A peregrinação também passou em frente à entrada que conduz ao sítio sagrado Guela Be'ñé(Estuário do Lagarto), que se encontrava com o acesso fechado, protegido por cercas e guardado por vigilantes armados que impediam a passagem dos peregrinos. Muitos dos que participaram da peregrinação sentiram, pela primeira vez, o impacto direto ocasionado pela implantação das torres eólicas: a mudança no trajeto decorrente das instalações, a privação por seguranças armados a locais antes acessíveis, a poluição sonora e visual causada pelos empreendimentos, a movimentação de caminhões e veículos e, especialmente, a mudança na forma de utilização do território comunal que antes era destinado à agricultura e hoje está tomado pelas torres eólicas. 
O ponto de chegada da caminhada foi uma área comunal à margem da chamada Lagoa Superior, onde as crianças aproveitaram para brincar e se refrescar. No centro do terreno estava a capela que recebeu a Santa Cruz e também muitos fiéis, muitos dos quais adentraram o recinto de joelhos e emocionados. Ao redor, um sem número de barracas montadas pelas famílias que ali recebem seus convidados e familiares para passar a noite, comer, beber, conversar, dançar, conviver.

A Santa Cruz dos Pescadores, assim como outras festas, mistura o aspecto religioso católico a uma tradição ancestral, nesse caso, a peregrinação a um local considerado sagrado que, acreditam os Binnizá, era realizada mesmo antes da chegada dos colonizadores e se mantêm como símbolo da sua identidade. São eventos cíclicos anuais que conjugam a cultura préhispânica à espanhola no sentido ritual dos elementos que nela aparecem (Manzo 1993: 154, tradução própria).

Dias antes da realização da Santa Cruz dos Pescadores ocorreu uma das mais tradicionais peregrinações de Juchitán a Santa Cruz Guela Be'ñe'(do Lagarto), em 2 de dezembro de 2013. Durante a caminhada, as pessoas também puderam observar as gigantescas torres eólicas do Parque Eólico Bii Hioxho, construído em 2 mil hectares de terras comunais. Devido às instalações, os caminhos tradicionalmente percorridos estavam cercados e as pessoas tiveram que passar por estradas abertas pelas empresas e que não identificam como suas rotas tradicionais. Também ficaram surpresas com o desmatamento provocado pelas construções, com o tráfego intenso de caminhões e máquinas nas terras comunais e, especialmente, com 0 forte aparato policial que guardava as torres eólicas.

Quando fomos caminhando na peregrinação de Guela Be'ñe' [do Lagarto] quase todo o caminho fizemos por uma estrada que não era a principal, onde ia a Santa Cruz. Preocuparam-se, talvez, os da Sociedade que a empresa não iria permitir a passagem por baixo das hélices, por que por aí era o caminho tradicional da Santa Cruz. Não sei o que houve que não fomos pelo lado das hélices, fomos por um caminho muito feio, sujo, que não foi limpo, não foi preparado para a passagem e chegou um momento em que, em vez de passarmos pelo caminho, nos meteram em um terreno. Cruzamos o terreno, entramos na estrada da empresa e logo passavam os carros aí. Não respeitaram que passava a Santa Cruz. E logo atrás de nós, vinham os policiais estaduais, os pistoleiros. Uns na frente $e$ outros atrás como que dizendo "aqui vão os bandidos, os delinquentes". (Maria Isabel Jimenez Salinas, Binnizá da 
sétima secção e integrante da $A P P J$, em entrevista à autora, 2013).

Para os integrantes da Assembleia Popular do Povo Juchiteco (APPJ), diretamente envolvidos na organização do ritual da Santa Cruz dos Pescadores, a manutenção das peregrinações também constitui uma forma de promover a resistência. Representa, de um lado, um meio de manutenção da autodeterminação indígena, de fortalecimento dos princípios comunitários e de apropriação dos espaços comunais requeridos pelas empresas; e, de outro, de levar a população a ter contato direto com os empreendimentos eólicos, tornando visível e palpável os impactos por eles causados.

Pôde-se observar que a peregrinação, realizada antes com um forte sentido cerimonial-festivo, congregou uma dimensão política em decorrência da apropriação das terras comunais pelas empresas eólicas em Juchitán. A procissão viabilizou atrair uma grande quantidade de pessoas do Bairro de Pescadores que, apesar de ouvir falar sobre a invasão dos projetos eólicos e as consequências destes para a vida coletiva, não tinha, até aquele momento, visualizado tais interferências sobre as terras comunais.

Dessa forma, a peregrinação possibilitou a construção de um olhar coletivo sobre a questão, baseado não mais em opiniões contrárias ou a favor dos empreendimentos, mas na experiência vivenciada de forma compartilhada. Muitos dos que ali estavam, viam de perto, pela primeira vez, os "gigantes" de ferro que moviam suas hélices por meio dos ventos, elemento tão importante na vida simbólica e material dos istmeños. Muitos questionaram a proximidade das torres dos seus caminhos rituais e, principalmente, do sítio sagrado, ponto final da Santa Cruz, uma vez que as torres instaladas por pelo Parque Eólico Bií Hioxo estavam a menos de um quilômetro do local.

Na Santa Cruz Guuze Benda (de los pescadores) está igual. Por aí começaram a instalar os ventiladores a uns 100 ou 200 metros da praia, da empresa Bií Hioxo. E estamos também preocupados até com esse nome, porque pertence aos Zapoteco e significa "ar forte", "vento forte" que passa a ideia de que o vento vem lavar os pulmóes, a refrescar-nos e que antes passava entre tantas árvores. Na parada San Vicente havia

\footnotetext{
${ }^{5} \mathrm{Na}$ Sétima Seção de Juchitán, o modelo das assembleias constitui a forma de mobilização política dos indígenas Binnizá. Para reagir à pressão das empresas e do governo que desejam avançar sobre seus territórios, os indígenas constituíram duas organizações, que atuam em forma de assembleias: a Assembleia dos Povos Indígenas do Istmo de Tehuantepec em Defesa da Terra e do Território (APIDTT) e a Assembleia Popular do Povo Juchiteco (APPJ). Tavares (2015)
} 
muitas árvores grandes e agora já as derrubaram, já as mataram. (Maria Isabel Jimenez Salinas, Binnizá da sétima secção e integrante da APPJ, em entrevista à autora, 2013).

É bastante evidente a preocupação dos indígenas com a apropriação de seus elementos culturais pelas empresas, como aconteceu com o uso da língua materna para nomear o Parque Eólico Bií Hioxo. Dizem ser uma estratégia de aproximação e publicidade utilizada para simular uma afinidade com a cultura local e mascarar o verdadeiro impacto que tais empreendimentos causam às populações locais.

\section{O território comunal}

O território comunal é o espaço em que a comunalidad se concretiza. 0 sentido da vida para os povos indígenas está completamente vinculado à sua existência territorializada e a terra assume o valor não de um bem econômico, somente produtivo, mas de uma

(...) mãe, que nos dá a vida, nos alimenta e recolhe em seu ventre. Nós pertencemos a ela e, por isso, não somos proprietários de terra alguma. Entre mãe e filho a relação não se define em termos de propriedade, mas de pertencimento mútuo (Díaz 2007: 40, tradução própria).

Díaz (op. cit.) atribui valor fundamental à terra. Afirma que quando os seres humanos entram em relação com a terra fazem isso de duas formas: através do trabalho e através dos ritos e cerimônias comunitárias. Mais do que terra, o espaço é compreendido enquanto território dotado de simbolismo e historicidade, e é o elemento que possibilita a conexão entre o meio físico e o espiritual. $\mathrm{O}$ autor afirma que o território é o mediador entre os seres humanos e o criador de vida, mas é também o que une todos os elementos da natureza - os astros, o barro, o milho, os seres humanos etc. - e o mundo espiritual.

Afirma que a terra não pertence ao homem, mas, ao contrário é o homem quem pertence à terra. Defende que tudo na natureza está relacionado e, para alguns povos, são os astros que determinam o tempo de vida dos seres que povoam a sua superfície. Para outros é o barro, arrancado das entranhas da terra e fácil de manusear para formar a figura do ser humano; ou ainda o milho, o fruto mais apreciado pelos Binnizá na relação que se estabelece entre os seres e a natureza e que brota da terra mediante o trabalho coletivo, o tequio. 
Cosmologicamente crê que o que acontece à terra, acontece aos filhos da terra e, por isso, os pais ensinam aos seus filhos que é preciso conversar com a terra antes de trabalhá-la ou que as árvores, aves e rios são seus irmãos. A filosofia da comunalidad mostra que devem ser feitos ritos e cerimônias para que as pessoas se deem conta de que a vida é o menor ponto do cosmos e também, talvez, um dos mais importantes da criação. A sacralidade da terra não os permite a divisão ou possessão, nem das pessoas sobre a terra e os recursos naturais, nem de pessoas sobre outras. Para um indígena, o ser humano não é o único com sentimento ou linguagem é um mais entre todos os seres vivos da natureza, sendo as plantas, rochas, montanhas, águas etc. seres que expressam e captam sentimentos (ibidem).

Todos os povos indígenas que habitam o Estado de Oaxaca, salvo o povo nahua (também conhecido por náhuatl), ocupam espaços de forma contínua até hoje, constituídos por um ou mais municípios e múltiplas comunidades (Barabas e Bartolomé apud Maldonado, 1999), ainda que o assentamento atual não seja o mesmo que o dos tempos pré-hispânicos (Maldonado, 2002). Existe entre os povos indígenas a noção generalizada de que o território étnico foi dado a cada povo por suas divindades ou forças sobrenaturais para interagir com a produção e reprodução da vida. Em todos esses territórios étnicos existem lugares sagrados que não pertencem a uma comunidade, mas ao "povo", pois foram as divindades que os concederam e com estas se estabelecem contatos rituais, por meio das cavernas, montanhas, rios e demais elementos da natureza. A sacralidade marca a geografia do território étnico e esses lugares são, em muitos casos, reconhecidos como tal e visitados inclusive por membros de diversos grupos étnicos (Barabas apud Maldonado, op. cit.).

O que a terra e os demais os elementos da comunalidad - trabalho, poder e festa comunais - significam nada mais é do que o valor das relações sociais que se estabelecem entre indivíduos e coletividades, tudo o que há na natureza e o mundo espiritual e enchem de sentido as comunidades indígenas de Oaxaca. A comunalidad como princípio vem reordenar as relações intra e extracomunitárias, bem como a relação entre as comunidades e seus territórios. Nesse fluxo, observa-se um movimento de constante trocas, elaborações e desconstruções que não se encerram como algo acabado, finalizado, mas em constante ressignificação.

\section{A comunalidade as novas/velhas territorialidades}

Muito já se explorou sobre o conceito de território para além de uma categoria político-jurídica estatal. O que os povos de Oaxaca nos aponta é 
para construção de uma reterritorialidade, a partir da sua resistência à apropriação externa de suas terras, recursos naturais e seus modos de vida. A vivência da comunalidad, enquanto base para sua resistência, vem ampliando a noção de território como algo que extrapola o elemento terra e incorpora a água e o ar enquanto dádivas que pertencem aos povos de Oaxaca e não podem ser apropriadas de forma estritamente mercantil.

Essa reterritorialização acontece em um espaço ampliado que rompe as barreiras das comunidades e provoca a reciprocidade e solidariedade, típicas da comunalidad, entre diferentes povos. Com a invasão das empresas eólicas atingindo diversos territórios indígenas, diferentes comunidades e etnias que antes não mantinham uma relação de reciprocidade tão próxima ou a mantinha especialmente em momentos festivos, passaram a compartilhar as experiências de tensão e conflito e a alimentar uma rede de reciprocidade e solidariedade no campo da ação política.

Esse fator é de suma importância para a manutenção de uma ampla e abrangente resistência aos projetos tendo em vista que as relações históricas entre os povos indígenas do Istmo levaram a um predomínio dos Binnizá (Zapoteco) diante dos demais povos, especialmente o povo Huave. Os povos indígenas dessa região incluem grupos das etnias Ikoots, Huave, Binnizá, Chontal, Zoque, Ayuuk (Mixe), Chinanteco, Nahua e Nuntajyi (Popoluca) (Manzo 2012). Historicamente, os Zapoteco têm se "beneficiado" do projeto modernizador diante dos demais, sobretudo desde o final do século XIX, o que se traduziu no enriquecimento da etnia à frente de outros grupos étnicos oaxaquenhos e na emergência de uma elite zapoteca (Suárez e Borusso 2006).

Segundo Toledo (2010), no sul do Istmo de Oaxaca, os zapotecos controlam as relações econômicas e políticas, há muito tempo, e seus territórios compreendem as melhores terras agrícolas, o que os colocou em vantagem com relação aos mareños, termo que designa de forma genérica os "povos do mar", ou seja, aos Huave e Ikoots que habitam os pueblos de San Mateo del Mar, San Dionisio del Mar, San Francisco del Mar e Santa María del Mar.

Para pensar a relação estabelecida entre os zapotecos e os mareños é preciso atentar para a ocupação territorial naquela região do Istmo de Oaxaca. A noção de "territorialização" (Pacheco de Oliveira 2004 [1999]) que se aplica ao processo vivenciado pelos povos indígenas do Nordeste do Brasil pode ser empregada para pensar a ocupação territorial dos istmeños, segundo a relação das sociedades com o território que se instaura a partir da presença colonial (idem 2004 [1999]). Também em Oaxaca ocorre um 
processo de reorganização social com a criação de novas unidades socioculturais mediante a afirmação de identidades étnicas; a adoção de mecanismos políticos próprios ou apropriados; a redefinição do controle social sobre os recursos naturais; e a reelaboração da cultura e da relação com o passado (ibidem) que define a territorialização.

A fim de compreender os processos sociais entre os povos indígenas da região do sul do Istmo de Oaxaca, é importante perceber que sua noção de territorialização está conformada por "terras e águas" (Toledo 2010: 262). Para eles, estes ambientes são complementares e a apropriação dos espaços aquáticos é entendida como uma prolongação dos espaços terrestres (ibidem). Existem as áreas de terras, em que os Zapoteco historicamente têm dominado com a agricultura, e as lagoas sobre as quais os mareños expandem seus domínios, exercendo uma participação mais modesta na economia e no poder regional. As relações acontecem de forma complementar, mas também por meio de disputas pela posse de áreas e recursos e pela dominação histórica de algumas comunidades sobre outras, especialmente as comandadas pelos zapotecos, mais ágeis politicamente com condutas estabelecidas desde o período colonial, sobre os demais povos.

Os Zapoteco criaram uma identidade "demonstrativa e orgulhosa" (ibidem: 258) com muita influência sobre os mareños, enquanto a identidade destes tem sido desvalorizada, estereotipada e estigmatizada pelos Zapoteco. Os Zapoteco também construíram internamente discursos e práticas comuns, visando construir uma unidade sobre sua identidade, o que não aconteceu entre os mareños, havendo dissensos internos até mesmo quanto à terminologia que os define. Segundo Toledo (op. cit.), em San Mateo del Mar, os Huave se autodenominam como Ikoots (que na língua indígena significa "nós") e o termo "huave" é visto por eles como uma terminologia imposta pelos Zapoteco com conotações pejorativas - que para Rueda (2011: 266) significaria "gente que apodrece na umidade". No entanto, nas outras comunidades Huave de San Dionisio del Mar, San Francisco del Mar e Santa María del Mar as pessoas se reconhecem como Huave e não como Ikoots (Toledo, op. cit.). Apesar da diferenciação na nomenclatura, todos pertencem a um mesmo povo e falam a mesma língua.

Por sua localização muito vinculada a Juchitán, os mareños mantêm um forte vínculo com os zapotecos dessa região, que também utilizam as lagoas junto a eles, para as atividades de pesca, o que os aproxima, mas também cria conflitos. Por exemplo, preferencialmente, os Ikoots de San Mateo exploram a Lagoa Inferior, que têm maior produtividade, e a Lagoa Superior é utilizada pelos Zapoteco, processo no qual se estabelece uma arena de 
disputa pelo desempenho da atividade econômica e também devido aos conflitos interétnicos históricos (Rueda, op. cit.).

Na relação assimétrica entre Zapoteco e mareños, Toledo (op. cit.) relata que os primeiros costumavam referir-se aos segundos como "índios", considerando que eles mesmos não o seriam, mas sim Zapoteco, um povo dominador que não se igualavam aos demais. Dentre os Huave, os Ikoots de San Mateo del Mar são considerados pelos regionais como o povo mais tradicional e conservador e, por isso, entendido muitas vezes como "menos civilizado". É este que concentra a maior população de falantes da língua huave e de pescadores que preservam as técnicas mais rudimentares para realizar a pesca e é também, entre os mareños, a comunidade cuja influência zapoteca é mais amenizada, justamente por essa forte presença e manutenção da cultura ikoots.

Outro aspecto que causa ruídos na relação entre os Zapoteco de Juchitán e os Ikoots de San Mateo está baseado em um antigo litígio existente entre San Mateo e a comunidade Huave vizinha de Santa María de Mar, que buscou apoio dos juchitecos e se transformou numa organização política muito ligada e dependente (Rueda, op. cit.: 267) destes. Por essa aproximação, administrativamente Santa María é vinculada à Juchitán, sendo uma agência deste (da mesma forma que Álvaro Obregón) e, consequentemente, ao Distrito de Juchitán, enquanto o vizinho San Mateo é um município vinculado ao Distrito de Tehuantepec.

Essas relações de dominação, mas também de complementariedade, entre os povos da terra (Zapoteco/Binnizá) e os do mar (Ikoots e Huave) têm sido definidas ao longo de muito tempo e baseadas em diversas situações históricas. O que interessa relatar aqui é a recente aproximação entre os Binnizá, Ikoots e Huave, devido à oposição de grande parte dos moradores dessas comunidades aos projetos eólicos.

Nesse sentido, uma observação se faz relevante. No processo de defesa dos territórios indígenas vivenciado pelos povos do sul do Istmo de Oaxaca, identificamos uma terceira noção de territorialização construída a partir dessa nova realidade. Trata-se de uma ressignificação do elemento "vento" enquanto um recurso próprio dessas populações, que, assim como a água e a terra, também deve ser defendido da apropriação e exploração pelas empresas estrangeiras.

Ouve-se da boca de muitas pessoas que o vento que as empresas querem transformar em energia é um patrimônio histórico que define os istmeños, por meio de uma relação indissociável entre homem e natureza. Dizia Pedro Orozco: 
Nos chamam para conversar e o que estamos dizendo é não, uma só palavra, não ao projeto eólico. Não queremos dinheiro, nem diálogo, nem negociação. O que vamos negociar? A lagoa, $o$ ar? Os recursos naturais não pedem ser negociados. Por aí estamos... o vento nos fornece as condiçóes para existirmos nesse território, mas o vento não nos pertence. Se querem explorá-lo devem perguntar às plantas, às abelhas, aos peixes, às montanhas que também dependem dele. Não podemos deixar que cheguem de fora e roubem nosso vento, que nos refresca o calor, que leva as sementes das plantas, esse mesmo vento que serviu aos nossos antepassados e que agora nos serve. (Pedro Orozco, mayordomo de Álvaro Obregón, em entrevista à autora, 2013).

O título de um documentário sobre o processo por que está passando a comunidade de San Dionisio del Mar a respeito da disputa pelo território com a empresa Mareña Renovables, resume bem a ideia do que os moradores pensam sobre isso: "Somos Vento". No filme, um narrador Huave diz: Somos o ar do Istmo. Somos o balançado das canoas levando pescados e camarões para casa. Em nossas terras, somos gente livre como o vento, sem pedir permissão a ninguém. Eles revelam uma relação cosmológica com o vento: O povo Ikoots é mágico. Nossos nahuales movem os sinos, movem os ventos (Comunidado da Assembleia dos Povos de San Dionisio del Mar, 8/2/2013). Nahual é um termo polissêmico que designa "o escondido", "o espírito", como também pode significar a capacidade de transformação do homem em animais ou elementos da natureza.

Os pescadores e camponeses do Istmo de Oaxaca sabem que dependem do vento para muitas coisas. A ideia de territorialização acrescida desse terceiro elemento que é o vento, revela, por parte dessas populações, uma noção integral do território, que passa a ser composto pelos elementos terra, mar e ar. A valoração externa desse elemento tão próprio às comunidades istmeñas, devido o interesse na sua exploração econômica, leva os indígenas a explicitar o valor desse bem para suas comunidades e a reivindicar que as empresas considerem que o vento também tem que ser pensado a partir dos significados e usos locais. Baseada nessa lógica, a Assembleia dos Povos Indígenas do Istmo em Defesa da Terra e do Território (APIDTT), importante movimento de resistência aos projetos eólicos, assina seus documentos com a seguinte frase: "A terra, o mar e o vento não se vende, se ama e se defende".

A Lagoa Inferior, território ocupado pelos Ikoots de San Mateo e Huave de Santa María, tem atraído o interesse das empresas eólicas devido ao local 
ser um ponto de confluência entre os ventos do norte e do sul, garantindo uma continuidade na captação do recurso energético, cujo potencial é avaliado acima de excelente. Quando as empresas chegaram a essa região, firmaram contratos com comuneros de Santa María (assim como aconteceu em Juchitán) para a utilização de dois mil hectares de terra, incluindo aí 60 hectares comunais que estão em disputa com San Mateo.

Diferentemente de Santa María, em San Mateo del Mar a PRENEAL MÉXICO S.A. não conseguiu fazer com que os comuneros de lá assinassem os contratos para a ocupação dos terrenos daquela localidade.

A comunidade de San Mateo del Mar, desde 2007, em uma assembleia geral de comuneros, acordou não permitir a presença das empresas transnacionais a respeito dos corredores eólicos. $A$ assembleia disse não ao projeto eólico por tudo que ele implica e, sobretudo, porque queremos proteger as áreas naturais que são as áreas em conflito com Santa María del Mar e que é, para nós, uma zona sagrada. Ali também estão as lagoas e há pasto para o gado. (Benito Canales, comunero Ikoots de San Mateo del Mar, em entrevista à autora, 2013).

Após um processo mais avançado de informação da população nestas zonas, as comunidades indígenas têm buscado se unir para fazer oposição às empresas e aos projetos eólicos nas terras comunais e ejidales. Uma das organizações que têm atuado nesse sentido é a APIIDTT. Apesar das diferenças e das disputas agrárias e étnicas, os povos do sul do Istmo de Oaxaca estão compreendendo que precisam agir conjuntamente diante do que consideram um inimigo comum: as empresas eólicas e o governo que as apoia.

\section{Considerações finais}

A observação empírica leva-nos a compreender a comunalidad, seja enquanto vivência comunitária ou enquanto fonte de valorização de epistemologias próprias aos povos indígenas de Oaxaca, em contraposição ao ordenamento hegemônico e suas tentativas de dominação, aniquilamento e homogeneização sociocultural. A comunalidad se alinha ao pensamento decolonial ao se constituir como alternativa a modelos impostos a partir de fora das realidades indígenas. Walsh (2013) já havia observado correlação similar no contexto equatoriano, de onde pinçou a partir do pensamento indígena a ideia de interculturalidade como um 
projeto político, social e epistêmico, cujo ponto central está no problema estrutural-colonial-racial e sua ligação com o capitalismo moderno.

No caso da comunalidad, atenta-se para o fato de sua concepção teórica não ser fruto de observação ou pesquisa de autores externos, mas proceder da vivência e reflexão dos próprios intelectuais indígenas. Da mesma forma que observada no contexto equatoriano, a comunalidad problematiza 0 legado colonial e suas consequências para os povos indígenas e se apresenta enquanto conceito definidor de uma realidade concreta e em constante atualização.

A resistência indígena em Oaxaca tem sido regida pela comunalidad, enquanto resgate de forma próprias de autodeterminação, mas também enquanto reelaboração dessa existência coletiva. A comunalidad se repensa e se reformula nas lutas e enfrentamentos do dia a dia, incorporando significados, inaugurando alianças, atualizando o pensamento indígena. É dessa forma que a comunalidad se coloca enquanto uma epistemologia indígena direcionada à autodeterminação dos povos e de descolonização das políticas estatais.

Observamos que a comunalidad é capaz de produzir categorias próprias para pensar a realidade indígena de Oaxaca numa perspectiva decolonial, reunindo esforços na tarefa de atualizar a tradição crítica do pensamento latino-americano ao inaugurar uma epistemologia baseada na característica fundante dos pueblos de Oaxaca, o caráter comunal, que integra os demais elementos que o compõem: o poder, o trabalho, as festas e o território comunais. A comunalidad surge como uma condição que une o modo de ser tradicional ao novo e se apresenta como elemento, ao mesmo tempo de resistência e ressignificação, dos povos indígenas enquanto sujeitos contemporâneos.

\section{Referências Bibliográficas}

AQUINO, Alejandra. La comunalidad como epistemología del Sur, aportes y retos. Cuadernos del Sur, v. 18, n. 34, p. 7-20, 2013.

AVENDAÑO, Lukas. Algunos lienzos y cartografía colonial en el Istmo. Mimeo, s/d.

BARABÁS, Alicia. Normatividades jurídicas en torno a las relocalizaciones de población indígena. In Derechos Indígenas en la actualidad, Inst. Inv. Jurídicas, UNAM, México: 1994.

CASANOVA, Pablo. Sociedad plural, colonialismo interno y desarrollo. América Latina, v. 6, n. 3, p. 15-32, 1963. 
CHENAUT, Victoria et al. (Ed.). Justicia y diversidad en América Latina: pueblos indígenas ante la globalización. Flacso-Sede Ecuador, 2011.

DIETZ, Gunther. Zapatismo y movimientos étnico-regionales en México. Nueva Sociedad, n. 140, pp. 33-50, 1995.

DÍAZ, Floriberto. In: ROBLES, Hernández Sofía e CARDOSO, Jiménez Rafael (compiladores). Floriberto Díaz Escrito. Comunalidad, energía viva del pensamiento mixe. Coleção Voces Indígenas. México: UNAM/Programa Universitario México Nación Multicultural, 2007.

DUSSEL, Enrique. Transmodernidade e interculturalidade: interpretação a partir da filosofia da libertação. Sociedade e Estado, v. 31, n. 1, p. 51-73, 2016.

Escobar, Arturo. Más allá del Tercer Mundo: globalización y diferencia. Bogotá: Instituto Colombiano de Antropología e Historia, Icanh, 2012.

ESTEVA, Gustavo. Sentido y alcances de la lucha por la autonomia. Texto apresentado na reunião da Latin American Studies Association, em Guadalajara, México, 1997.

FANON, Frantz. Pele negra, máscaras brancas. SciELO-EDUFBA, 2008 [1965].

HERNÁNDEZ-DÍAZ, Jorge. La política del reconocimiento, la diversidad electoral y la defensa de la identidad colectiva en Oaxaca. In: Diez voces a diez años. Refexiones sobre los usos y costumbres a diez años del reconocimiento legal. México: Educa, 2005.

JANCSÓ, Katalin. La Guelaguetza-Una fiesta moderna de México. In: Acta Universitatis Szegediensis. Universidad De Szeged, Hungría: setembro, 2003.

LUNA, Jaime Martinez. Comunalidad y Autonomía. Disponível na biblioteca digital: http://espora.org/biblioweb/ México: 2002.

Comunalidad y desarrollo. Cultura Indígena, conaculta/campo ac, México, 2003.

MALDONADO, Benjamín. Autonomía y Comunalidad India-Enfoques y Propuestas desde Oaxaca. Centro INAH Oaxaca: Oaxaca, 2002.

MANZO, Carlos. Comunalidad y resistencia. In: El México indígena bajo la mira. Universidade de Guadalajara, México: De Vinculación y Ciencia, maio de 2008.

MANZO, Manuel. Los zapotecos del Istmo em el fin de siglo. In: Etnicidad, nacionalismo y poder, tres ensaios. Oaxaca: Universidad Autonoma Benito Juarez, 1993. 
MIGNOLO, Walter. A colonialidade de cabo a rabo: o hemisfério ocidental no horizonte conceitual da modernidade. A colonialidade do saber: Eurocentrismo e ciências sociais. Perspectivas latino-americanas, p. 71-103, 2005 .

NAVA MORALES, Elena. Totopo no ar: radio e comunalidad em Oaxaca, México. UNB: 2014.

OUDIJK, Michel e FRIZZI, María. Los títulos primordiales. Un género de tradición mesoamericana del mundo prehispánico al siglo XXI. Relaciones 95, vol. XXIV, 2003.

PACHECO DE OLIVEIRA, João. Uma etnologia dos "índios misturados"? Situação colonial, territorialização e fluxos culturais. In: OLIVEIRA, João Pacheco de (org.). A viagem da volta: etnicidade, política e reelaboração cultural no Nordeste indígena. 2. ed. RJ: Contra Capa, 2004 [1999].

QUIJANO, Aníbal. Colonialidad del poder, cultura y conocimiento en América Latina. Anuario Mariateguiano (Lima: Amauta) Vol. IX, № 9, 1997. . Colonialidade do poder, Eurocentrismo e América Latina. Buenos Aires: CLACSO, 2005.

RENDÓN, Juan. La comunalidad o modo de vida comunal de los pueblos indios. Tomo I. México: Dirección General de Culturas Populares e Indígenas, 2004.

RUEDA, Elisa Cruz. Eólicos e inversión privada: El caso de San Mateo del Mar, en el Istmo de Tehuantepec Oaxaca. The Journal of Latin American and Caribbean Anthropology, v. 16, n. 2, p. 257-277, 2011.

SAID, Edward. Orientalismo - O Oriente como invenção do Ocidente. São Paulo: Companhia das Letras. 2007.

SANTOS, Boaventura; MENESES, M. (Org.). Epistemologias do Sul. São Paulo: Cortez, 2010.

SUÁREZ, Águeda e BORUSSO, Marinella. Dimensiones simbólicas sobre el sistema sexo/género entre los indígenas zapotecas del Istmo de Tehuantepec (México). Gazeta de Antropología, n.22, artículo 2, 2006.

TAVARES, Clarissa. Tradições políticas de resistência indígena: a organização dos povos do Ceará (Brasil) e de Oaxaca (México) diante de projetos de desenvolvimento em seus territórios. UNB: 2015.

TOLEDO, Ezequiel. La territorialización entre mareños y zapotecos en el sistema lagunário del sur del istmo de Tahuantepec. In: Dalton Palomo (et. 
al.). Aproximaciones a la región del Istmo. Diversidad multiétnica y socioeconómica en una region estratégica para el país. Oaxaca, México: Conaculta, 2010.

WALSH, Catherine. Interculturalidad y (de) colonialidad: perspectivas críticas y políticas. Visão Global, v. 15, n. 1-2, p. 61-74, 2013.

WALLERSTEIN, Immanuel. Creación del sistema mundial moderno. In: Luis Peña Luis Bernardo (ed.), Un mundo jamás imaginado, p. 1492-1992, 1992.

ZEITLIN, Judith. Recordando a los reyes. El Lienzo de Guevea y el discurso histórico de la época colonial. In: Escritura Zapoteca 2, 500 años de historia. María Frizzi (coord.). CIESAS, CONACULTA-INAH, México, 2003. 